TI 2002-124/4

Tinbergen Institute Discussion Paper

\title{
A Joint Framework for Category Purchase and Consumption Behavior
}

\author{
Rutger van Oest \\ Richard Paap \\ Philip Hans Franses
}


Tinbergen Institute

The Tinbergen Institute is the institute for economic research of the Erasmus Universiteit Rotterdam, Universiteit van Amsterdam and

Vrije Universiteit Amsterdam.

Tinbergen I nstitute Amsterdam

Keizersgracht 482

1017 EG Amsterdam

The Netherlands

Tel.: +31.(0)20.5513500

Fax: $\quad+31 .(0) 20.5513555$

Tinbergen Institute Rotterdam

Burg. Oudlaan 50

3062 PA Rotterdam

The Netherlands

Tel.: $\quad+31 .(0) 10.4088900$

Fax: $\quad+31 .(0) 10.4089031$

Most TI discussion papers can be downloaded at

http://www.tinbergen.nl 


\title{
A Joint Framework for Category Purchase and Consumption Behavior
}

\author{
Rutger van Oest* \\ Tinbergen Institute \\ Erasmus University Rotterdam \\ Richard Paap \\ Econometric Institute \\ Erasmus University Rotterdam \\ Philip Hans Franses \\ Econometric Institute \\ Erasmus University Rotterdam
}

${ }^{*}$ Corresponding author: Tinbergen Institute, H16-32, Erasmus University Rotterdam, P.O. Box 1738, 3000 DR Rotterdam (e-mail vanoest@few.eur.nl, tel. +31-10-4088946, FAX +31-104089162). We wish to thank Lennart Hoogerheide for his assistance in obtaining the proofs of the results in Appendix B. Additionally, Dennis Fok is thanked for his help with the data. The results in the paper have been obtained using Ox v2.20 (Doornik 1998). 


\title{
A Joint Framework for Category Purchase and Consumption Behavior
}

\begin{abstract}
We propose a consistent utility-based framework to jointly explain a household's decisions on purchase incidence, brand choice and purchase quantity. The approach differs from other approaches, currently available in the literature, as it is able to take into account consumption dynamics. In the model, households derive utility from consumption, and they relate their purchase behavior to consumption planning. We illustrate our model for yogurt purchases, and show that our model yields important additional insights. One such insight is that the reservation price of households is not fixed, but depends on the available inventory stock. Furthermore, we find that promotional activities increase sales through more purchases in the product category and brand switching, but the effect through larger purchase quantities is limited.
\end{abstract}

\section{Keywords}

purchase incidence, brand choice, purchase quantity, consumption, utility maximization 


\section{Introduction}

The purchase decision process of households can be decomposed into three components, that is, the "whether to buy from the product category" component, the "brand choice" component and the "purchase quantity" component. All three decisions may be influenced by promotional activities, such as features or price discounts, of which the effects are of central interest in the marketing literature. Several models have been proposed to measure these effects and to explain consumer purchase behavior. Gupta (1988) puts forward a model in which the three purchase decisions are treated independently, Bucklin and Lattin (1991) consider purchase incidence and brand choice, Jedidi, Mela and Gupta (1999) look at the brand choice and purchase quantity decisions, and Mela, Jedidi and Bowman (1998) focus on purchase incidence and purchase quantity. Note that all these studies take a partial approach, in the sense that at least one of the possible interdependencies between the three purchase decision components is ignored. We are aware of only two studies, that is, Chiang (1991) and Chintagunta (1993), where the authors provide consistent utility-based frameworks to describe all three purchase decisions simultaneously.

The models put forward by Chiang (1991) and Chintagunta (1993), which aim to capture all components of purchase behavior and which also have strong microeconomic foundations, do suffer from a few limitations. First and most importantly, the two models involve utility specifications which are based on the number of units purchased instead of the number of units consumed. We believe however that utility would be derived from consumption, as this is the ultimate goal of a purchase, and hence it should not come from the purchasing activity itself. By relating utility to the quantity purchased, it is implicitly assumed that there does not exist a time gap between the purchase occasion and consumption of the purchased amount, that is, the entire amount is consumed instantaneously. This seems to be rather implausible for storable product categories. Hence, the models of Chiang (1991) and Chintagunta (1993) ignore consumption dynamics. Indeed, a purchase from a storable product category results in more future consumption opportunities due to 
a larger inventory stock. In order to maximize utility, a household should relate its purchase behavior to consumption planning, and this amounts to a dynamic process. This relationship between purchasing and consumption tends to be neglected. From a conceptual point of view, the two models imply that households do not have inventory stock, as they only make purchases for instantaneous consumption.

Another drawback of the purchase behavior frameworks of Chiang (1991) and Chintagunta (1993) is the specification of the purchase quantity component. As a matter of fact, both models end up with a regression type model for purchase quantity, and this is implausible for two reasons. First, it does not rule out negative purchase quantities, while the amount purchased should obviously be positive. Second, most consumption goods are packaged goods, which are sold in fixed amounts. A standard regression model is not able to take this into account, as it assumes continuous purchase quantities. Even though this regression framework is frequently used in the literature, see Jedidi, Mela and Gupta (1999), Mela, Jedidi and Bowman (1998), Neslin, Henderson and Quelch (1985), an alternative approach based on the Poisson regression model, which results in positive and discrete purchase quantities, is more plausible. Such a model is also used by Ailawadi and Neslin (1998), and Bucklin, Gupta and Siddarth (1998a,b).

In this paper we also introduce a utility-based and joint framework for purchase incidence, brand choice and purchase quantity. In contrast to the models of Chiang (1991) and Chintagunta (1993), our framework is (i) able to take into account consumption dynamics, and (ii) it yields positive and discrete purchase quantities, as in the Poisson regression model. Similar to the models of Chiang (1991) and Chintagunta (1993), purchase incidence, brand choice and purchase quantity share the same source of uncertainty, and their probabilities are derived from utility maximization principles.

The remainder of the paper is organized as follows. In Section 2, we put forward our joint framework for category purchase and consumption behavior. In Section 3, we illustrate our model for yogurt purchases, and we compare it with the model of 
Chintagunta (1993). Although the framework of Chintagunta (1993) is more flexible, as he introduces three additional parameters in the purchase quantity part, our model does not perform much worse in terms of predictive power. However, our model gives more insights into the purchase and consumption process of households. We further find that some of the price elasticities, computed from our utility framework, differ substantially from the elasticities, computed from the model of Chintagunta (1993). In Section 4, we end with some conclusions.

\section{The model}

In this section, we put forward our model for purchase incidence, brand choice and purchase quantity.

\subsection{Outline}

Our model is based on the notion that a household, contemplating a purchase during a shopping trip, compares the amount to be paid with the utility gain due to additional consumption opportunities. The household considers purchasing the brand giving the largest gain in utility per dollar spent. If this utility gain outweighs the expenditure, then the household purchases the brand, and the household keeps on purchasing additional units, as long as utility derived from buying an additional unit outweighs the monetary costs. The gain in consumption utility is computed by comparing the household's optimal consumption paths with and without the additional unit added to the inventory stock. So, purchase behavior is related to consumption planning.

In our model it is assumed that the consumption decision is considered prior to the purchase decision. Each time, a household decides which amount to consume from its inventory stock, but the subsequent purchase decision is only considered during shopping trips. This conditional approach is based on the heuristic principle that households are only exposed to promotional activities during shopping trips. The approach is frequently pursued in the marketing literature, see Ailawadi and 
Neslin (1998), Bucklin and Lattin (1991), Chintagunta (1993), among many others. If a household makes a purchase from the product category, it also has to decide on the brand and the purchase quantity.

\subsection{Available inventory}

At the beginning of time $t$, a household $i$ determines its available inventory $S_{i, t}$. Clearly, it is defined by the relation

$$
S_{i, t}=S_{i, t-1}+Q_{i, t-1}-C_{i, t-1}
$$

where $S_{i, t-1}$ is the available inventory at the beginning of time $t-1, Q_{i, t-1}$ is the amount purchased at time $t-1$, and $C_{i, t-1}$ is the amount consumed at time $t-1$.

\subsection{Consumption decision}

For the consumption decision of households, we assume that households are forwardlooking utility maximizers with some finite planning horizon. Each household chooses its consumption levels such that total discounted utility, which is achieved until the planning horizon, is maximized under the condition that total consumption cannot exceed available inventory. The considered planning horizon is allowed to vary over households, and it depends on the particular situation that a household faces.

In the consumption model, households have constant relative risk aversion (CRRA) utility, that is, household $i$ derives instantaneous utility, defined as

$$
u\left(C_{i, t}\right)=\frac{C_{i, t}^{1-\theta}}{1-\theta} \quad \text { with } \quad 0<\theta<1
$$

from consuming $C_{i, t}$ units at time $t$. This utility specification involves one curvature parameter $\theta$, which can be interpreted as a measure of risk aversion, see Romer (1996).

If $T_{i, t}$ denotes the planning horizon for household $i$ at time $t$, then the household's dynamic utility maximization problem is given by

$$
\begin{aligned}
& \max _{\left\{C_{i, s}\right\}_{s=t}^{t+T_{i, t}}} \sum_{s=t}^{t+T_{i, t}} \frac{1}{(1+\rho)^{s-t}} u\left(C_{i, s}\right), \\
& \text { subject to } \quad \sum_{s=t}^{t+T_{i, t}} C_{i, s} \leq S_{i, t} \text {, }
\end{aligned}
$$


where $\rho>0$ is a discount rate for time. Given this, it can be shown that the optimal consumption path is defined by

$$
\begin{aligned}
C_{i, t} & =S_{i, t} \frac{1-\nu}{1-\nu^{T_{i, t}+1}}, \\
C_{i, t+s} & =\nu^{s} C_{i, t}, \quad s=1, \ldots, T_{i, t},
\end{aligned}
$$

where $\nu=(1+\rho)^{-\frac{1}{\theta}}$ is the dampening factor, see Appendix A. This consumption path yields utility level $U$, given by

$$
\begin{aligned}
U\left(S_{i, t}\right) & =\sum_{s=t}^{t+T_{i, t}} \frac{1}{(1+\rho)^{s-t}} \frac{C_{i, s}^{1-\theta}}{1-\theta} \\
& =\sum_{s=0}^{T_{i, t}} \frac{1}{(1+\rho)^{s}} \frac{\left(\nu^{s} C_{i, t}\right)^{1-\theta}}{1-\theta} \\
& =\frac{C_{i, t}{ }^{1-\theta}}{1-\theta} \sum_{s=0}^{T_{i, t}}\left(\frac{\nu^{1-\theta}}{1+\rho}\right)^{s} \\
& =\frac{C_{i, t}{ }^{1-\theta}}{1-\theta} \sum_{s=0}^{T_{i, t}} \nu^{s} \\
& =\frac{C_{i, t}{ }^{1-\theta}}{1-\theta} \frac{1-\nu^{T_{i, t}+1}}{1-\nu} \\
& =\frac{C_{i, t}-\theta}{1-\theta} S_{i, t}
\end{aligned}
$$

where $C_{i, t}$ is defined by (5). We note that maximum achievable utility $U$ as a function of the available inventory $S_{i, t}$ is the so-called indirect utility function. As household $i$ consumes amount $C_{i, t}$ at time $t$, it ends up with inventory level $S_{i, t}-C_{i, t}$ after consumption. This is the inventory level which is taken into account in the subsequent purchase decision.

The planning horizon $T_{i, t}$ in (5) is not observed, and it therefore has to be estimated. We impose that this planning horizon is proportional to the time period which is needed to deplete the current inventory stock when consumption is at the household's average level, that is,

$$
T_{i, t}=\exp (\delta) \frac{S_{i, t}}{\bar{C}_{i}}
$$

where $\exp (\delta)$ is the proportionality factor, and $\bar{C}_{i}$ denotes the average consumption rate of household $i$. Substituting (8) into (5) gives the optimal current consumption 
level

$$
C_{i, t}=S_{i, t} \frac{1-\nu}{1-\nu^{\frac{\exp (\delta) S_{i, t}+\bar{C}_{i}}{\bar{C}_{i}}}},
$$

which is increasing in both the inventory level $S_{i, t}$ and the household's average consumption rate $\bar{C}_{i}$. The indirect utility function $U$ turns out to be concave for this consumption specification, see Appendix B. This concavity is an essential property of our model.

\subsection{Purchase decision}

The purchase decision of household $i$ at time $t$ can be expected to depend on both the inventory level remaining after consumption, that is, $S_{i, t}-C_{i, t}$, and the attractiveness of the various brands in the product category under scrutiny. We assume that purchasing $q$ units of brand $j \in\{1,2, \ldots, J\}$ provides net utility

$$
\gamma_{i, j, t}\left[U\left(S_{i, t}-C_{i, t}+q\right)-U\left(S_{i, t}-C_{i, t}\right)\right]-P_{i, j, t} q
$$

where $P_{i, j, t}$ is the price of brand $j$, and $\gamma_{i, j, t}$ can be interpreted as the quality of brand $j$ perceived by household $i$. We note that the opportunity cost of going to the store does not need to be taken into account. It is "sunk", as conditioning on shopping trips implies that the shopping trip is made anyway.

Net utility (10) is defined as the gain in consumption utility, resulting from the purchased amount, minus the involved expenditure $P_{i, j, t} q$. The term between square brackets is the difference between the utility levels which can be achieved with and without the purchased $q$ units. It is the gain in utility due to increased consumption opportunities. As this utility gain is entirely caused by adding units of brand $j$ to the inventory stock, it is premultiplied by $\gamma_{i, j, t}$ in order to allow for brand-specific effects.

Following Hanemann (1984), Chiang (1991) and Chintagunta (1993), we define the brand quality $\gamma_{i, j, t}$ by

$$
\gamma_{i, j, t}=\exp \left(M_{i, j, t}{ }^{\prime} \beta+\varepsilon_{i, j, t}\right)
$$


where $M_{i, j, t}$ contains intrinsic brand preferences, a brand loyalty variable and an indicator variable for non-price promotion (either a feature or display). We further include the household's average consumption rate and an indicator variable for whether the product category has been purchased during the previous shopping trip. The latter two variables can be interpreted as being related to the household's appreciation for the entire product category. Inclusion of the consumption rate can explain that heavy users buy more than light users. Furthermore, a purchase at the previous shopping trip can be expected to increase appreciation through a memory effect. As these two variables do not vary over brands, they add the same value to all perceived brand qualities. The random term $\varepsilon_{i, j, t}$ in $\gamma_{i, j, t}$ is assumed to be independently and identically distributed, and it obeys an extreme value distribution. So, $\varepsilon_{i, j, t}$ has density

$$
f(\varepsilon)=\exp (-\varepsilon) \exp (-\exp (-\varepsilon))
$$

and cumulative density

$$
F(\varepsilon)=\operatorname{Pr}\left(\varepsilon_{i, j, t} \leq \varepsilon\right)=\exp (-\exp (-\varepsilon))
$$

This random disturbance, which is not observed by the researcher, affects all three purchase decisions, that is, purchase incidence, brand choice and purchase quantity. For notational convenience, the shorthand notation

$$
V_{i, t}(q) \equiv U\left(S_{i, t}-C_{i, t}+q\right)
$$

is used in the sequel of this paper, so that net utility (10) is replaced by

$$
\gamma_{i, j, t}\left[V_{i, t}(q)-V_{i, t}(0)\right]-P_{i, j, t} q
$$

\subsubsection{Purchase incidence}

The first decision to be made during a shopping trip is whether to purchase a brand from a product category at all. In order to derive the probability that household $i$ makes a purchase during shopping trip $t$, we use concavity of the indirect utility function $U$, which, in turn, implies that the net utility (15), as a function of the 
purchase quantity $q$, is also concave. Using this latter concavity property, a necessary and sufficient condition for not making a purchase is that, for all brands, not purchasing is preferred over purchasing one unit. In other words, for all brands, purchasing one unit should give negative net utility. It immediately follows from (15) that this no-purchase condition translates into

$$
\frac{\gamma_{i, k, t}\left[V_{i, t}(1)-V_{i, t}(0)\right]}{P_{i, k, t}}<1, \quad k=1, \ldots, J,
$$

stating that one dollar kept in pocket (having value 1) gives higher utility than one dollar spent on any of the brands. The no-purchase probability is given by

$$
\begin{aligned}
\operatorname{Pr}\left(Y_{i, t}=0\right) & =\operatorname{Pr}\left(\frac{\gamma_{i, k, t}\left[V_{i, t}(1)-V_{i, t}(0)\right]}{P_{i, k, t}}<1, k=1, \ldots, J\right) \\
& =\operatorname{Pr}\left(\varepsilon_{i, k, t}<\ln \left(\frac{P_{i, k, t}}{\exp \left(M_{i, k, t}{ }^{\prime} \beta\right)\left[V_{i, t}(1)-V_{i, t}(0)\right]}\right), k=1, \ldots, J\right) \\
& =\prod_{k=1}^{J} \exp \left(-\exp \left(-\left[\ln \left(\frac{P_{i, k, t}}{\exp \left(M_{i, k, t^{\prime}} \beta\right)\left[V_{i, t}(1)-V_{i, t}(0)\right]}\right)\right]\right)\right) \\
& =\exp \left(-\left[V_{i, t}(1)-V_{i, t}(0)\right] \sum_{k=1}^{J} \exp \left(\mu_{i, k, t}\right)\right),
\end{aligned}
$$

where $Y_{i, t}$ is the indicator variable for purchase incidence, and

$$
\mu_{i, k, t} \equiv M_{i, k, t}{ }^{\prime} \beta-\ln \left(P_{i, k, t}\right)
$$

The purchase incidence probability, which is the complement of (17), is now given by

$$
\operatorname{Pr}\left(Y_{i, t}=1\right)=1-\exp \left(-\left[V_{i, t}(1)-V_{i, t}(0)\right] \sum_{k=1}^{J} \exp \left(\mu_{i, k, t}\right)\right)
$$

The purchase incidence probability (19) is determined by two components, that is, $V_{i, t}(1)-V_{i, t}(0)$ and $\sum_{k=1}^{J} \exp \left(\mu_{i, k, t}\right)$. The first component implies that a lower inventory level $S_{i, t}$ makes a purchase more likely, as $U$ is concave and the inventory level after consumption, $S_{i, t}-C_{i, t}$, is increasing in $S_{i, t}$ (see Appendix B), so that the difference $V_{i, t}(1)-V_{i, t}(0)=U\left(S_{i, t}-C_{i, t}+1\right)-U\left(S_{i, t}-C_{i, t}\right)$ is decreasing in $S_{i, t}$. The second component, which is related to the category value variable defined in Ben-Akiva and Lerman (1985), implies that the probability of purchase incidence increases when the product category becomes more attractive in terms of promotional activities. Both relationships are plausible. 


\subsubsection{Brand choice}

The brand choice decision is considered conditional on purchase incidence. Hence, it is given that one dollar spent on the selected brand provides more utility than one dollar kept in pocket. However, it would still be suboptimal to choose that brand if there would exist another brand, providing even more utility for the same dollar. So, household $i$ selects brand $j$ at shopping trip $t$ if and only if it provides a higher utility gain per dollar than any of the other brands, that is,

$$
\frac{\gamma_{i, j, t}\left[V_{i, t}(q)-V_{i, t}(0)\right]}{P_{i, j, t} q}>\frac{\gamma_{i, k, t}\left[V_{i, t}(q)-V_{i, t}(0)\right]}{P_{i, k, t} q}, \quad k \neq j .
$$

This condition results in a probability of selecting brand $j$, which is given by

$$
\begin{aligned}
\operatorname{Pr}\left(B_{i, t}=j \mid Y_{i, t}=1\right) & =\operatorname{Pr}\left(\frac{\gamma_{i, j, t}\left[V_{i, t}(q)-V_{i, t}(0)\right]}{P_{i, j, t} q}>\frac{\gamma_{i, k, t}\left[V_{i, t}(q)-V_{i, t}(0)\right]}{P_{i, k, t} q}, k \neq j\right) \\
& =\operatorname{Pr}\left(\frac{\gamma_{i, j, t}}{P_{i, j, t}}>\frac{\gamma_{i, k, t}}{P_{i, k, t}}, k \neq j\right) \\
& =\operatorname{Pr}\left(\mu_{i, j, t}+\varepsilon_{i, j, t}>\mu_{i, k, t}+\varepsilon_{i, k, t}, k \neq j\right) \\
& =\frac{\exp \left(\mu_{i, j, t}\right)}{\sum_{k=1}^{J} \exp \left(\mu_{i, k, t}\right)},
\end{aligned}
$$

where $B_{i, t}$ is the brand variable and $\mu_{i, k, t}$ is defined by (18). We end up with the conditional logit framework, initially proposed by McFadden (1974). It is seen from (21) that the brand providing the highest utility gain per dollar does not depend on the purchased amount $q$, nor does it depend on the available inventory stock $S_{i, t}-C_{i, t}$. We finally note that the average consumption rate and the purchase-atprevious-shopping-trip indicator do not affect brand choice. As these two variables do not vary over the brands, they drop out.

\subsubsection{Purchase quantity}

The purchase quantity decision is considered conditional on purchase incidence and brand choice. It is seen from net utility (15) that household $i$ prefers purchasing $q \geq 1$ units of brand $j$ over $q-1$ units if and only if

$$
\gamma_{i, j, t}\left[V_{i, t}(q)-V_{i, t}(0)\right]-P_{i, j, t} q>\gamma_{i, j, t}\left[V_{i, t}(q-1)-V_{i, t}(0)\right]-P_{i, j, t}(q-1) .
$$


This condition can be rewritten as

$$
\frac{\gamma_{i, j, t}\left[V_{i, t}(q)-V_{i, t}(q-1)\right]}{P_{i, j, t}}>1,
$$

stating that the utility gain per dollar spent on the $q$-th unit should be larger than 1 , which is the utility derived from keeping the dollar in pocket. As the indirect utility function $U$ is concave, the left-hand side of (23) is decreasing in $q$. So, additional units are purchased as long as spending one dollar provides more utility than keeping one dollar in pocket.

In order to find the probability distribution of the purchase quantity $Q_{i, t}$, we proceed as follows. First, it should be noted that the purchase incidence condition requires that purchasing one unit is preferred over not purchasing, that is, $1 \succ 0$, where $\succ$ denotes "is preferred over". Further, the household only has an incentive to purchase precisely $q$ units if it gives a higher net utility level than all other quantities, that is, $q \succ 0, q \succ 1, \ldots, q \succ q-1, q \succ q+1, q \succ q+2, \ldots$. As net utility (15) is concave in $q$, a sufficient condition for this optimality is that purchasing $q$ units is preferred over buying one unit less and buying one unit more, that is, $q \succ q-1$ and $q \succ q+1$. In terms of preference relations, the probability of purchasing $q$ units is now defined by

$$
\operatorname{Pr}(q \succ q-1, q \succ q+1 \mid 1 \succ 0)
$$

As net utility (15) implies that

$$
\begin{aligned}
& q \succ q-1 \Leftrightarrow \varepsilon_{i, j, t}>-\mu_{i, j, t}-\ln \left[V_{i, t}(q)-V_{i, t}(q-1)\right], \\
& q \succ q+1 \Leftrightarrow \varepsilon_{i, j, t}<-\mu_{i, j, t}-\ln \left[V_{i, t}(q+1)-V_{i, t}(q)\right],
\end{aligned}
$$

the probability that household $i$ purchases $q$ units of brand $j$ becomes

$$
\begin{aligned}
& \operatorname{Pr}\left(Q_{i, t}=q \mid Y_{i, t}=1, B_{i, t}=j\right) \\
= & \operatorname{Pr}\left(-\mu_{i, j, t}-\ln \left[V_{i, t}(q)-V_{i, t}(q-1)\right]<\varepsilon_{i, j, t}<-\mu_{i, j, t}-\ln \left[V_{i, t}(q+1)-V_{i, t}(q)\right] \mid\right. \\
& \left.\varepsilon_{i, j, t}>-\mu_{i, j, t}-\ln \left[V_{i, t}(1)-V_{i, t}(0)\right]\right) \\
= & \frac{\operatorname{Pr}\left(-\mu_{i, j, t}-\ln \left[V_{i, t}(q)-V_{i, t}(q-1)\right]<\varepsilon_{i, j, t}<-\mu_{i, j, t}-\ln \left[V_{i, t}(q+1)-V_{i, t}(q)\right]\right)}{\operatorname{Pr}\left(\varepsilon_{i, j, t}>-\mu_{i, j, t}-\ln \left[V_{i, t}(1)-V_{i, t}(0)\right]\right)}
\end{aligned}
$$




$$
\begin{aligned}
& =\frac{\operatorname{Pr}\left(\varepsilon_{i, j, t}<-\mu_{i, j, t}-\ln \left[V_{i, t}(q+1)-V_{i, t}(q)\right]\right)-\operatorname{Pr}\left(\varepsilon_{i, j, t}<-\mu_{i, j, t}-\ln \left[V_{i, t}(q)-V_{i, t}(q-1)\right]\right)}{1-\operatorname{Pr}\left(\varepsilon_{i, j, t}<-\mu_{i, j, t}-\ln \left[V_{i, t}(1)-V_{i, t}(0)\right]\right)} \\
& =\frac{\exp \left(-\left[V_{i, t}(q+1)-V_{i, t}(q)\right] \exp \left(\mu_{i, j, t}\right)\right)-\exp \left(-\left[V_{i, t}(q)-V_{i, t}(q-1)\right] \exp \left(\mu_{i, j, t}\right)\right)}{1-\exp \left(-\left[V_{i, t}(1)-V_{i, t}(0)\right] \exp \left(\mu_{i, j, t}\right)\right)}
\end{aligned}
$$

where $\mu_{i, j, t}$ is defined by (18). However, for the sake of efficiency, it is advisable to impose some maximum value $q_{\max }$ for the purchased amount. The truncated probability distribution is then defined by

$$
\begin{aligned}
& \operatorname{Pr}\left(Q_{i, t}=q \mid Y_{i, t}=1, B_{i, t}=j\right) \\
= & \frac{\exp \left(-\left[V_{i, t}(q+1)-V_{i, t}(q)\right] \exp \left(\mu_{i, j, t}\right)\right)-\exp \left(-\left[V_{i, t}(q)-V_{i, t}(q-1)\right] \exp \left(\mu_{i, j, t}\right)\right)}{\exp \left(-\left[V_{i, t}\left(q_{\max }+1\right)-V_{i, t}\left(q_{\max }\right)\right] \exp \left(\mu_{i, j, t}\right)\right)-\exp \left(-\left[V_{i, t}(1)-V_{i, t}(0)\right] \exp \left(\mu_{i, j, t}\right)\right)}
\end{aligned}
$$

for $1 \leq q \leq q_{\max }$.

\subsection{Parameter estimation}

The parameters of the model can be estimated using maximum likelihood [ML]. The likelihood function for the joint model is given by

$$
\begin{aligned}
L= & \prod_{i} \prod_{t}\left[\left[\operatorname{Pr}\left(Y_{i, t}=1\right)\right]^{y_{i, t}}\left[\operatorname{Pr}\left(Y_{i, t}=0\right)\right]^{\left(1-y_{i, t}\right)}\right. \\
& {\left.\left[\prod_{j}\left(\operatorname{Pr}\left(B_{i, t}=j \mid Y_{i, t}=1\right) \operatorname{Pr}\left(Q_{i, t}=q_{i, t} \mid Y_{i, t}=1, B_{i, t}=j\right)\right)^{I\left\{b_{i, t}=j\right\}}\right]\right], }
\end{aligned}
$$

where $y_{i, t}, b_{i, t}$ and $q_{i, t}$ are realizations of the purchase incidence variable $Y_{i, t}$, the brand choice variable $B_{i, t}$ and the purchase quantity variable $Q_{i, t}$, respectively. Numerical techniques have to be used to get the ML parameter estimates. Details can be obtained from the corresponding author.

\subsection{An alternative model}

To conclude this section, we briefly discuss the purchase decision model of Chintagunta (1993), and we highlight the differences between this model and ours. In the model, households maximize their utility during shopping trips. They derive utility from both the amount purchased from the product category under scrutiny, while accounting for brand differences, and the amount of money spent on a "composite good", representing all other goods purchased. Utility is maximized under the 
condition that the amount of money spent on both the product category and the composite good does not exceed the total realized expenditure during the shopping trip. So, there is a budget restriction involved, which is binding.

The model of Chintagunta (1993) concerns a purchase incidence probability

$$
\operatorname{Pr}\left(Y_{i, t}=1\right)=1-\exp \left(-R \sum_{k=1}^{J} \exp \left(\mu_{i, k, t}\right)\right),
$$

where $\mu_{i, k, t}$ is defined by (18), and $R$ is the reservation price for the product category. This reservation price is defined such that households are not willing to purchase a brand if its price, after accounting for the brand's quality, exceeds $R$. The nopurchase condition for household $i$ at shopping trip $t$ is that

$$
\frac{P_{i, k, t}}{\gamma_{i, k, t}}>R, \quad k=1 \ldots, J
$$

For identification purposes, either one of the intrinsic brand preferences has to be set at 0 , or the reservation price $R$ has to be normalized at 1 . So, the reservation price is only identified relatively to a base brand.

In our model, the whether to buy decision of households can also be put into a reservation price context. The no-purchase condition (16) can be written as

$$
\frac{P_{i, k, t}}{\gamma_{i, k, t}}>V_{i, t}(1)-V_{i, t}(0), \quad k=1 \ldots, J
$$

where the right-hand side can be interpreted as the reservation price. We note that this reservation price depends on the available inventory stock $S_{i, t}$. As $V_{i, t}(1)-V_{i, t}(0)$ is decreasing in $S_{i, t}$, households are willing to pay more for the same level of quality when the inventory level is low than they are willing to pay in the opposite case. So, the reservation price depends on the urgency of a purchase, and we believe that this is an important implication.

The second decision in the purchase process of households is brand choice. In the model of Chintagunta (1993), the probability that household $i$ selects brand $j$ is given by

$$
\operatorname{Pr}\left(B_{i, t}=j \mid Y_{i, t}=1\right)=\frac{\exp \left(\mu_{i, j, t}\right)}{\sum_{k=1}^{J} \exp \left(\mu_{i, k, t}\right)},
$$

which coincides with the brand choice probability in our model. 
Finally, the purchase quantity component in the model of Chintagunta (1993) is given by

$$
P_{i, j, t} Q_{i, t}=\phi_{1}+\phi_{2} E X P_{i, t}+\phi_{3}\left(\sum_{k=1}^{J} \exp \left(\mu_{i, k, t}\right)\right)^{-1}+\lambda_{i, j, t},
$$

where $E X P_{i, t}$ is the total expenditure by household $i$ during shopping trip $t$, and $\lambda_{i, j, t}$ follows the extreme value distribution, shifted such that it has zero mean. Equation (34) states that the expenditure on the product category is explained by the total expenditure during the shopping trip, and the inverse of the "category value" $\sum_{k=1}^{J} \exp \left(\mu_{i, k, t}\right)$. However, in contrast to our model, this regression setting does not result in discrete purchase quantities, nor does it ensure that the amount purchased is positive. We further note that three new parameters are introduced in (34), implying that the purchase quantity decision is not strongly connected to the purchase incidence and brand choice decisions.

\section{An empirical illustration}

In this section, we apply our model to an A.C. Nielsen scanner panel data set on yogurt purchases. We discuss the results, and we compare the predictive performance and the estimated price-promotion elasticities with the model of Chintagunta (1993).

\subsection{Data}

In the application, we consider A.C. Nielsen scanner panel data on yogurt purchases in the Sioux Falls, South Dakota, market. The considered period consists of 92 weeks, and it runs from November 1986 to August 1988. We focus on six brands, which together account for more than $75 \%$ of the category sales in units. These brands are Dannon, Nordica, QC, W.B.B., Weight Watchers and Yoplait.

The first 46 weeks of the considered period are used for initialization, while the remaining 46 weeks are used for both estimation and out-of-sample model validation. Only households which make at least one shopping trip every two weeks and which have at least four purchase incidences in the 46-week initialization period are considered in the analysis. The latter condition is used in order to avoid serious dis- 
tortions due to improper initialization. By doing so, we end up with 147 households, 15054 shopping trips and 2895 purchases. The estimation sample consists of $80 \%$ of these households, and the remaining $20 \%$ is assigned to a hold-out sample. In our analysis, purchase quantity, inventory and consumption are measured in multiples of six ounces.

\subsection{Estimation results}

In both our model and the model of Chintagunta (1993), we define the brand quality $\gamma_{i, j, t}$ as

$$
\gamma_{i, j, t}=\exp \left(\beta_{0, j}+\beta_{1} B L_{i, j, t}+\beta_{2} P R_{i, j, t}+\beta_{3} \bar{C}_{i}+\beta_{4} Y_{i, t-1}+\varepsilon_{i, j, t}\right),
$$

where $B L_{i, j, t}$ is an exponentially weighted average of past brand choice, see Guadagni and Little (1983), $P R_{i, j, t}$ is an indicator variable for promotion (either a feature or display), $\bar{C}_{i}$ is the household's average consumption rate, computed as the number of units purchased during the initialization period divided by the number of days, and $Y_{i, t-1}$ is an indicator variable for whether the product category has been purchased during the previous shopping trip.

In our model, the inventory variable $S_{i, t}$ is initialized by setting it at the household's average purchase quantity, which is computed from the same initialization period as $\bar{C}_{i}$. We note that no inventory variable is included in the model of Chintagunta (1993), as this model implicitly assumes instantaneous consumption. For model identification, we normalize the reservation price $R$ at 1 . In both models, the purchase incidence, brand choice and purchase quantity components are estimated simultaneously using maximum likelihood [ML]. Finally, we note that, in our model, the probability distribution for purchase quantity is truncated at $q_{\max }=20$, which is the largest purchase quantity observed in the sample.

Insert Table 1 about here. 


\subsubsection{Parameter estimates}

The parameter estimates are reported in Table 1. It is seen from the table that, for both models, all response parameters have the expected sign and are significant at the $1 \%$ level. The perceived quality of a brand increases with the household's degree of loyalty to that brand, and a non-price promotion also has a positive impact. Further, a household's appreciation for the product category is higher if, on average, the household consumes more of it, and it is also higher if the product category has been purchased during the previous shopping trip. So, there is a memory effect after a purchase.

In the purchase quantity part of the model of Chintagunta (1993), the parameter $\phi_{2}$ indicates that a larger total expenditure during a shopping trip is likely to result in a larger amount of yogurt purchased. Furthermore, the parameter $\phi_{3}$ shows a positive relationship between the "category value" $\sum_{k=1}^{J} \exp \left(\mu_{i, k, t}\right)$ and the purchased amount of yogurt. Both effects are as expected.

In our model, the estimates for the discount rate $\rho$ and the curvature parameter $\theta$ result in a consumption dampening factor $\nu=(1+\rho)^{-\frac{1}{\theta}}=0.846$. Furthermore, the parameter $\delta$, which is not significantly different from 0 , indicates that the consumption planning horizon of households is approximately equal to the inventory depletion time $\frac{S_{i, t}}{\bar{C}_{i}}$.

Insert Figure 1 about here.

For illustrative purposes, we display the "reservation price" $V_{i, t}(1)-V_{i, t}(0)$ as a function of $S_{i, t}-C_{i, t}$, which is the inventory level taken into account during a shopping trip. This is done for an "average household", having a consumption rate of 0.136 units per day. Figure 1 shows that a household is willing to pay more for the same level of quality when its inventory stock becomes smaller. Moreover, the closer a household gets to depletion of its inventory stock, the faster its reservation price increases. So, a household's reservation price is clearly not fixed, as is assumed in Chintagunta (1993), as it depends on the urgency of a purchase. 
Insert Table 2 about here.

\subsubsection{Predictive performance}

Next, we consider the predictive performance of the two models. These are reported in Table 2. It is seen from the table that the purchase incidence and brand choice components in our model are able to compete with the model of Chintagunta (1993). On the other hand, the predictive power concerning the purchase quantity is slightly worse, as the Root Mean Squared Error [RMSE] is larger, both in-sample and outof-sample. However, the difference in RMSE values is not large. The slightly better performance of the model of Chintagunta (1993) is due to three new parameters for purchase quantity. This results in a purchase quantity component, which is estimated almost separately from the two other components. Although our model is less flexible, as the purchase quantity decision is strongly connected to the purchase incidence and brand choice decisions, it does not perform much worse than the model of Chintagunta (1993). This demonstrates the empirical validity of our model.

\section{Insert Table 3 about here.}

\subsubsection{Estimated elasticities}

Finally, we compare the elasticities of the price and promotion variables, computed from the two models. The elasticities for Dannon, Nordica and Yoplait, which are the three largest brands in the sample, are reported in Table 3. These elasticities have been averaged over the estimation sample. The definitions, which are used, can be found in Appendix C. Table 3 shows that the elasticities for purchase incidence and brand choice do not differ much across the two models, although the estimated non-price promotion elasticities are slightly larger in our model. On the other hand, there are large differences in the elasticities for purchase quantity. Our model implies that price only has a marginal effect on the quantity purchased, whereas the model of Chintagunta (1993) actually imposes price elasticities being smaller than -1 for reasonable parameter values, see (C.8) in Appendix C. 
In sum, both our model and the model of Chintagunta (1993) imply that sales can be increased through promotional activities. However, the origins of this increase in sales are different. According to our utility framework, the bulk of this sales increase is only explained by more purchases and brand switching, and not by larger purchase quantities. This is in contrast with the model of Chintagunta (1993) in which larger purchase quantities are also found to play an important role.

\section{Conclusions}

In this paper we proposed a consistent utility-based framework for jointly explaining a household's decisions on purchase incidence, brand choice and purchase quantity. The approach differs from other approaches, currently available in the literature, as it accounts for consumption dynamics.

Our model is based on the notion that a household, contemplating a purchase during a shopping trip, compares the amount to be paid with the utility gain due to additional consumption opportunities. The household considers purchasing the brand giving the largest gain in utility per dollar spent. If this utility gain outweighs the expenditure, then the household purchases the brand, and the household keeps on purchasing additional units, as long as utility derived from buying an additional unit outweighs the monetary costs. The gain in consumption utility is computed by comparing the household's optimal consumption paths with and without the additional unit added to the inventory stock. So, purchase behavior is related to consumption planning.

We illustrated our framework for yogurt purchases, and we compared it with the model of Chintagunta (1993) in which the purchase quantity component is estimated almost separately from the purchase incidence and brand choice components. Although our model is less flexible, as the purchase quantity decision is strongly connected to the purchase incidence and brand choice decisions, it did not perform much worse than the model of Chintagunta (1993). This demonstrated the empirical validity of our model. 
Next, we compared the elasticities of the price and promotion variables, computed from the two models. It turned out that both our model and the model of Chintagunta (1993) imply that sales can be increased through promotional activities. According to our utility framework, this sales increase is mainly explained by more purchases and brand switching, and not by larger purchase quantities, which is in contrast with the model of Chintagunta (1993). 


\section{Appendix A}

The optimization problem

$$
\begin{aligned}
& \max _{\left\{C_{i, s}\right\}_{s=t}^{t+T_{i, t}}} \sum_{s=t}^{t+T_{i, t}} \frac{1}{(1+\rho)^{s-t}} u\left(C_{i, s}\right), \quad u\left(C_{i, s}\right)=\frac{C_{i, s}{ }^{1-\theta}}{1-\theta}, \\
& \text { subject to } \quad \sum_{s=t}^{t+T_{i, t}} C_{i, s} \leq S_{i, t} \text {, }
\end{aligned}
$$

can be solved using the Euler equation approach. The Lagrangian is defined by

$$
\mathcal{L}=\sum_{s=t}^{t+T_{i, t}}\left[\frac{1}{(1+\rho)^{s-t}} \frac{C_{i, s}{ }^{1-\theta}}{1-\theta}\right]-\lambda\left[\sum_{s=t}^{t+T_{i, t}} C_{i, s}-S_{i, t}\right],
$$

where $\lambda$ denotes the "shadow price" of inventory. The first-order conditions at time $s$ and time $s-1, s=t+1, t+2, \ldots, t+T_{i, t}$, are given by

$$
\begin{aligned}
\frac{1}{(1+\rho)^{s-t}} C_{i, s}^{-\theta} & =\lambda, \\
\frac{1}{(1+\rho)^{s-t-1}} C_{i, s-1}^{-\theta} & =\lambda,
\end{aligned}
$$

respectively. It immediately follows from (A.4) and (A.5) that

$$
\frac{1}{(1+\rho)^{s-t}} C_{i, s}^{-\theta}=\frac{1}{(1+\rho)^{s-t-1}} C_{i, s-1}^{-\theta},
$$

which can be rewritten as

$$
C_{i, s}=\nu C_{i, s-1} \quad \text { with } \quad \nu=(1+\rho)^{-\frac{1}{\theta}} .
$$

Condition (A.7) describes the dynamics of the optimal consumption path, where $\nu$ is the dampening factor. Following this consumption path, total consumption until the planning horizon equals

$$
\sum_{s=t}^{t+T_{i, t}} C_{i, s}=C_{i, t} \sum_{s=0}^{T_{i, t}} \nu^{s}=C_{i, t} \frac{1-\nu^{T_{i, t}+1}}{1-\nu} \quad \text { with } \quad \nu=(1+\rho)^{-\frac{1}{\theta}}
$$

for given current consumption $C_{i, t}$. Next, we note that the inventory restriction (A.2) is binding, as utility is strictly increasing in consumption, that is, more consumption always gives higher utility. Substituting (A.8) into the inventory restriction, and some rewriting, gives consumption $C_{i, t}$ as a function of available inventory $S_{i, t}$ and the planning horizon $T_{i, t}$, that is,

$$
C_{i, t}=S_{i, t} \frac{1-\nu}{1-\nu^{T_{i, t}+1}} \quad \text { with } \quad \nu=(1+\rho)^{-\frac{1}{\theta}} .
$$




\section{Appendix B}

This appendix contains two analytical results for our model. We only show the final steps. The full derivations can be obtained from the corresponding author.

First, the indirect utility function $U$, defined by (5), (7) and (8), is concave in the inventory level $S_{i, t}$, as the condition that the second-order derivative is negative can be rewritten as

$$
\begin{aligned}
& -(1-\theta)\left[\bar{C}_{i} \theta\left((1+\rho) \frac{\exp (\delta) S_{i, t}+\bar{C}_{i}}{\bar{C}_{i} \theta}-1\right)-\ln \left[(1+\rho)^{\left.\left.\exp (\delta) S_{i, t}\right]\right]^{2}}\right.\right. \\
& -\left((1+\rho) \frac{\exp (\delta) S_{i, t}+\bar{C}_{i}}{\bar{C}_{i} \theta}-1\right)\left[\ln \left[(1+\rho)^{\exp (\delta) S_{i, t}}\right]\right]^{2}<0,
\end{aligned}
$$

which clearly holds for all $S_{i, t}>0, \bar{C}_{i}>0, \delta \in R, 0<\theta<1$, and $\rho>0$.

Second, the inventory level after consumption, $S_{i, t}-C_{i, t}$ is increasing in the inventory level before consumption, $S_{i, t}$, as the condition that the first-order derivative is positive can be rewritten as

$$
\bar{C}_{i} \nu\left(1-\nu^{\frac{\exp (\delta) S_{i, t}}{\bar{C}_{i}}}\right)\left(1-\nu^{\frac{\exp (\delta) S_{i, t}+\bar{C}_{i}}{\bar{C}_{i}}}\right)+\exp (\delta) S_{i, t}(\nu-1) \ln (\nu) \nu^{\frac{\exp (\delta) S_{i, t}+\bar{C}_{i}}{\bar{C}_{i}}}>0
$$

which clearly holds for all $S_{i, t}>0, \bar{C}_{i}>0, \delta \in R$, and $0<\nu<1$. 


\section{Appendix C}

In this appendix we define the elasticities which are used in this paper. For our model, the price elasticity for purchase incidence is given by

$$
\frac{\partial \operatorname{Pr}\left(Y_{i, t}=1\right)}{\partial P_{i, j, t}} \frac{P_{i, j, t}}{\operatorname{Pr}\left(Y_{i, t}=1\right)}=-\left[V_{i, t}(1)-V_{i, t}(0)\right] \exp \left(\mu_{i, j, t}\right) \frac{\operatorname{Pr}\left(Y_{i, t}=0\right)}{\operatorname{Pr}\left(Y_{i, t}=1\right)},
$$

the own price elasticity for brand choice is given by

$$
\frac{\partial \operatorname{Pr}\left(B_{i, t}=j \mid Y_{i, t}=1\right)}{\partial P_{i, j, t}} \frac{P_{i, j, t}}{\operatorname{Pr}\left(B_{i, t}=j \mid Y_{i, t}=1\right)}=\operatorname{Pr}\left(B_{i, t}=j \mid Y_{i, t}=1\right)-1,
$$

the cross price elasticity for brand choice is given by

$$
\frac{\partial \operatorname{Pr}\left(B_{i, t}=k \mid Y_{i, t}=1\right)}{\partial P_{i, j, t}} \frac{P_{i, j, t}}{\operatorname{Pr}\left(B_{i, t}=k \mid Y_{i, t}=1\right)}=\operatorname{Pr}\left(B_{i, t}=j \mid Y_{i, t}=1\right), \quad k \neq j,
$$

and the price elasticity for purchase quantity is given by

$$
\frac{\partial E\left(Q_{i, t} \mid Y_{i, t}=1, B_{i, t}=j\right)}{\partial P_{i, j, t}} \frac{P_{i, j, t}}{E\left(Q_{i, t} \mid Y_{i, t}=1, B_{i, t}=j\right)},
$$

where $E(\cdot)$ denotes the expectation. The first-order derivative in (C.4) is computed as the increase in $E\left(Q_{i, t} \mid Y_{i, t}=1, B_{i, t}=j\right)$ when the price of brand $j$ is increased by a small step, divided by the step size.

For the model of Chintagunta (1993), the price elasticity for purchase incidence is given by

$$
\frac{\partial \operatorname{Pr}\left(Y_{i, t}=1\right)}{\partial P_{i, j, t}} \frac{P_{i, j, t}}{\operatorname{Pr}\left(Y_{i, t}=1\right)}=-R \exp \left(\mu_{i, j, t}\right) \frac{\operatorname{Pr}\left(Y_{i, t}=0\right)}{\operatorname{Pr}\left(Y_{i, t}=1\right)},
$$

the own price elasticity for brand choice is given by

$$
\frac{\partial \operatorname{Pr}\left(B_{i, t}=j \mid Y_{i, t}=1\right)}{\partial P_{i, j, t}} \frac{P_{i, j, t}}{\operatorname{Pr}\left(B_{i, t}=j \mid Y_{i, t}=1\right)}=\operatorname{Pr}\left(B_{i, t}=j \mid Y_{i, t}=1\right)-1,
$$

the cross price elasticity for brand choice is given by

$$
\frac{\partial \operatorname{Pr}\left(B_{i, t}=k \mid Y_{i, t}=1\right)}{\partial P_{i, j, t}} \frac{P_{i, j, t}}{\operatorname{Pr}\left(B_{i, t}=k \mid Y_{i, t}=1\right)}=\operatorname{Pr}\left(B_{i, t}=j \mid Y_{i, t}=1\right), \quad k \neq j,
$$

and the price elasticity for purchase quantity is given by

$$
\begin{aligned}
& \frac{\partial E\left(Q_{i, t} \mid Y_{i, t}=1, B_{i, t}=j\right)}{\partial P_{i, j, t}} \frac{P_{i, j, t}}{E\left(Q_{i, t} \mid Y_{i, t}=1, B_{i, t}=j\right)} \\
= & \frac{\phi_{3} \exp \left(\mu_{i, j, t}\right)\left[\sum_{k=1}^{J} \exp \left(\mu_{i, k, t}\right)\right]^{-2}}{\phi_{1}+\phi_{2} E X P_{i, t}+\phi_{3}\left[\sum_{k=1}^{J} \exp \left(\mu_{i, k, t}\right)\right]^{-1}}-1,
\end{aligned}
$$


where $E(\cdot)$ denotes the expectation.

For both models, the promotion elasticities $(\times 100)$ are defined as the percentage increase in probability/expectation due to promotion of the brand, while the promotion variables for the other brands are kept at their actual values. 


\section{References}

Ailawadi K.L. and S.A. Neslin (1998), "The Effect of Promotion on Consumption: Buying More and Consuming It Faster", Journal of Marketing Research, 35 (August), $390-398$.

Ben-Akiva M. and S.R. Lerman (1985), Discrete Choice Analysis, Cambridge, MA: MIT Press.

Bucklin R.E., S. Gupta and S. Siddarth (1998a), "Determining Segmentation in Sales Response Across Consumer Purchase Behaviors", Journal of Marketing Research, 35 (May), 189-197.

Bucklin R.E., S. Gupta and S. Siddarth (1998b), "Modelling the Effect of Purchase Quantity on Consumer Choice of Product Assortment", Journal of Forecasting, 17, $281-301$.

Bucklin R.E. and J.M. Lattin (1991), "A Two-State Model of Purchase Incidence and Brand Choice", Marketing Science, 10 (1), 24-39.

Chiang J. (1991), "A Simultaneous Approach to the Whether, What and How Much to Buy Questions", Marketing Science, 10 (4), 297-315.

Chintagunta P.K. (1993), "Investigating Purchase Incidence, Brand Choice and Purchase Quantity Decisions of Households", Marketing Science, 12 (2), 184-208.

Doornik J.A. (1998), Object-Oriented Matrix Programming using Ox 2.0, Timberlake Consultants, London, http://www.nuff.ox.ac.uk/Users/Doornik.

Guadagni P.M. and J.D.C. Little (1983), “A Logit Model of Brand Choice Calibrated on Scanner Data", Marketing Science, 2 (3), 203-238.

Gupta S. (1988), "Impact of Sales Promotions on When, What, and How Much to Buy", Journal of Marketing Research, 25 (November), 342-355.

Hanemann W.M. (1984), "Discrete/Continuous Models of Consumer Demand", 
Econometrica, 52 (3), 541-561.

Jedidi K., C.F. Mela and S. Gupta (1999), "Managing Advertising and Promotion for Long-Run Profitability", Marketing Science, 18 (1), 1-22.

McFadden D. (1974), "Conditional Logit Analysis of Qualitative Choice Behavior", in P. Zarembka (ed.), Frontiers in Econometrics, Chapter 4, Academic Press.

Mela C.F., K. Jedidi and D. Bowman (1998), "The Long-Term Impact of Promotions on Consumer Stockpiling Behavior", Journal of Marketing Research, 35 (May), $250-262$.

Neslin S.A., C. Henderson and J. Quelch (1985), "Consumer Promotions and the Acceleration of Product Purchases", Marketing Science, 4 (2), 147-165.

Romer D. (1996), Advanced Macroeconomics, McGraw-Hill. 
Table 1: Parameter estimates for our model and the model of Chintagunta (1993). The standard errors are given in parentheses.

\begin{tabular}{|c|c|c|}
\hline & our model & Chintagunta (1993) \\
\hline \multirow[t]{2}{*}{ Dannon } & $-3.203^{* * *}$ & $-2.964^{* * *}$ \\
\hline & $(0.116)$ & $(0.100)$ \\
\hline \multirow[t]{2}{*}{ Nordica } & $-3.151^{* * *}$ & $-2.926^{* * *}$ \\
\hline & $(0.107)$ & $(0.089)$ \\
\hline \multirow[t]{2}{*}{$\mathrm{QC}$} & $-5.296^{* * *}$ & $-5.030^{* * *}$ \\
\hline & $(0.314)$ & $(0.303)$ \\
\hline \multirow[t]{2}{*}{ W.B.B. } & $-3.432^{* * *}$ & $-3.208^{* * *}$ \\
\hline & $(0.112)$ & $(0.096)$ \\
\hline \multirow[t]{2}{*}{ Weight Watchers } & $-4.049^{* * *}$ & $-3.780^{* * *}$ \\
\hline & $(0.196)$ & $(0.182)$ \\
\hline \multirow[t]{2}{*}{ Yoplait } & $-2.709^{* * *}$ & $-2.475^{* * *}$ \\
\hline & $(0.113)$ & $(0.093)$ \\
\hline \multirow[t]{2}{*}{ brand loyalty $^{a}$} & $0.311^{* * *}$ & $0.313^{* * *}$ \\
\hline & $(0.010)$ & $(0.009)$ \\
\hline \multirow[t]{2}{*}{ promotion } & $0.553^{* * *}$ & $0.530^{* * *}$ \\
\hline & $(0.121)$ & $(0.123)$ \\
\hline \multirow[t]{2}{*}{ average consumption } & $0.152^{* * *}$ & $0.142^{* * *}$ \\
\hline & $(0.012)$ & $(0.011)$ \\
\hline \multirow[t]{2}{*}{ lagged incidence } & $1.027^{* * *}$ & $0.870^{* * *}$ \\
\hline & $(0.076)$ & $(0.070)$ \\
\hline \multirow[t]{2}{*}{$\rho^{b}$} & $0.023^{* * *}$ & \\
\hline & $(0.006)$ & \\
\hline \multirow[t]{2}{*}{$\theta$} & $0.135^{* * *}$ & \\
\hline & $(0.036)$ & \\
\hline \multirow[t]{2}{*}{$\delta$} & 0.123 & \\
\hline & $(0.099)$ & \\
\hline \multirow[t]{2}{*}{$\overline{\phi_{1}}$} & & $2.052^{* * *}$ \\
\hline & & $(0.056)$ \\
\hline \multirow[t]{2}{*}{$\phi_{2}$} & & $0.116^{* * *}$ \\
\hline & & $(0.040)$ \\
\hline \multirow[t]{2}{*}{$\phi_{3}$} & & $-3.372^{* * *}$ \\
\hline & & $(0.927)$ \\
\hline
\end{tabular}

*** significant at $1 \%$.

$a$ : The carry-over parameter is estimated at 0.730 .

$b$ : $\rho$ from (3), $\theta$ from (2), $\delta$ from (8), $\phi_{1}, \phi_{2}, \phi_{3}$ from (34). 
Table 2: In-sample and out-of-sample predictive performances of our model and the model of Chintagunta (1993).

\begin{tabular}{|c|c|c|c|c|}
\hline \multicolumn{5}{|c|}{ in-sample prediction-realization table for purchase incidence } \\
\hline & \multicolumn{2}{|c|}{ our model } & \multicolumn{2}{|c|}{ Chintagunta (1993) } \\
\hline & predict no & predict yes & predict no & predict yes \\
\hline observe no & 61.2 & 19.8 & 60.7 & 20.3 \\
\hline observe yes & 8.2 & 10.8 & 7.9 & 11.0 \\
\hline \multicolumn{5}{|c|}{ out-of-sample prediction-realization table for purchase incidence } \\
\hline & \multicolumn{2}{|c|}{ our model } & \multicolumn{2}{|c|}{ Chintagunta (1993) } \\
\hline & predict no & predict yes & predict no & predict yes \\
\hline observe no & 68.0 & 20.8 & 68.1 & 20.7 \\
\hline \multirow[t]{3}{*}{ observe yes } & 7.7 & 3.5 & 7.7 & 3.5 \\
\hline & \multicolumn{2}{|c|}{ our model } & \multicolumn{2}{|c|}{ Chintagunta (1993) } \\
\hline & in-sample & out-of-sample & in-sample & out-of-sample \\
\hline hit rate brand choice & 73.8 & 67.8 & 73.8 & 67.8 \\
\hline RMSE purchase quantity & 2.97 & 2.60 & 2.48 & 2.45 \\
\hline
\end{tabular}


Table 3: Estimated elasticities resulting from our model and the model of Chintagunta (1993).

\begin{tabular}{|c|c|c|c|c|c|c|}
\hline \multicolumn{7}{|c|}{ elasticities for purchase incidence } \\
\hline & \multicolumn{3}{|c|}{ our model } & \multicolumn{3}{|c|}{ Chintagunta (1993) } \\
\hline & \multicolumn{2}{|l|}{ price } & promotion & \multicolumn{2}{|l|}{ price } & romotion \\
\hline Dannon & \multicolumn{2}{|c|}{-0.162} & 0.115 & \multicolumn{2}{|c|}{-0.162} & 0.109 \\
\hline Nordica & \multicolumn{2}{|c|}{-0.289} & 0.201 & \multicolumn{2}{|c|}{-0.288} & 0.190 \\
\hline Yoplait & \multicolumn{2}{|c|}{-0.254} & 0.177 & \multicolumn{3}{|r|}{0.168} \\
\hline \multicolumn{7}{|c|}{ price elasticities for brand choice } \\
\hline & \multicolumn{3}{|c|}{ our model } & \multicolumn{3}{|c|}{ Chintagunta (1993) } \\
\hline & Dannon & Nordica & Yoplait & Dannon & Nordica & Yoplait \\
\hline Dannon & -0.819 & 0.181 & 0.181 & -0.818 & 0.182 & 0.182 \\
\hline Nordica & 0.295 & -0.705 & 0.295 & 0.294 & -0.706 & 0.294 \\
\hline Yoplait & 0.347 & 0.347 & -0.653 & 0.348 & 0.348 & -0.652 \\
\hline
\end{tabular}

promotion elasticities for brand choice

$$
\text { our model Chintagunta (1993) }
$$

Dannon Nordica Yoplait Dannon Nordica Yoplait

Dannon $\quad 0.567 \quad-0.099 \quad-0.099 \quad 0.538 \quad-0.095 \quad-0.095$

$\begin{array}{lllllll}\text { Nordica } & -0.150 & 0.477 & -0.150 & -0.144 & 0.455 & -0.144\end{array}$

$\begin{array}{lllllll}\text { Yoplait } & -0.175 & -0.175 & 0.434 & -0.168 & -0.168 & 0.413\end{array}$

elasticities for purchase quantity

our model Chintagunta (1993)

\begin{tabular}{lcccc} 
& price & promotion & price & promotion \\
Dannon & -0.016 & 0.012 & -1.043 & 0.021 \\
Nordica & -0.018 & 0.011 & -1.053 & 0.027 \\
Yoplait & -0.030 & 0.022 & -1.035 & 0.016 \\
\hline
\end{tabular}




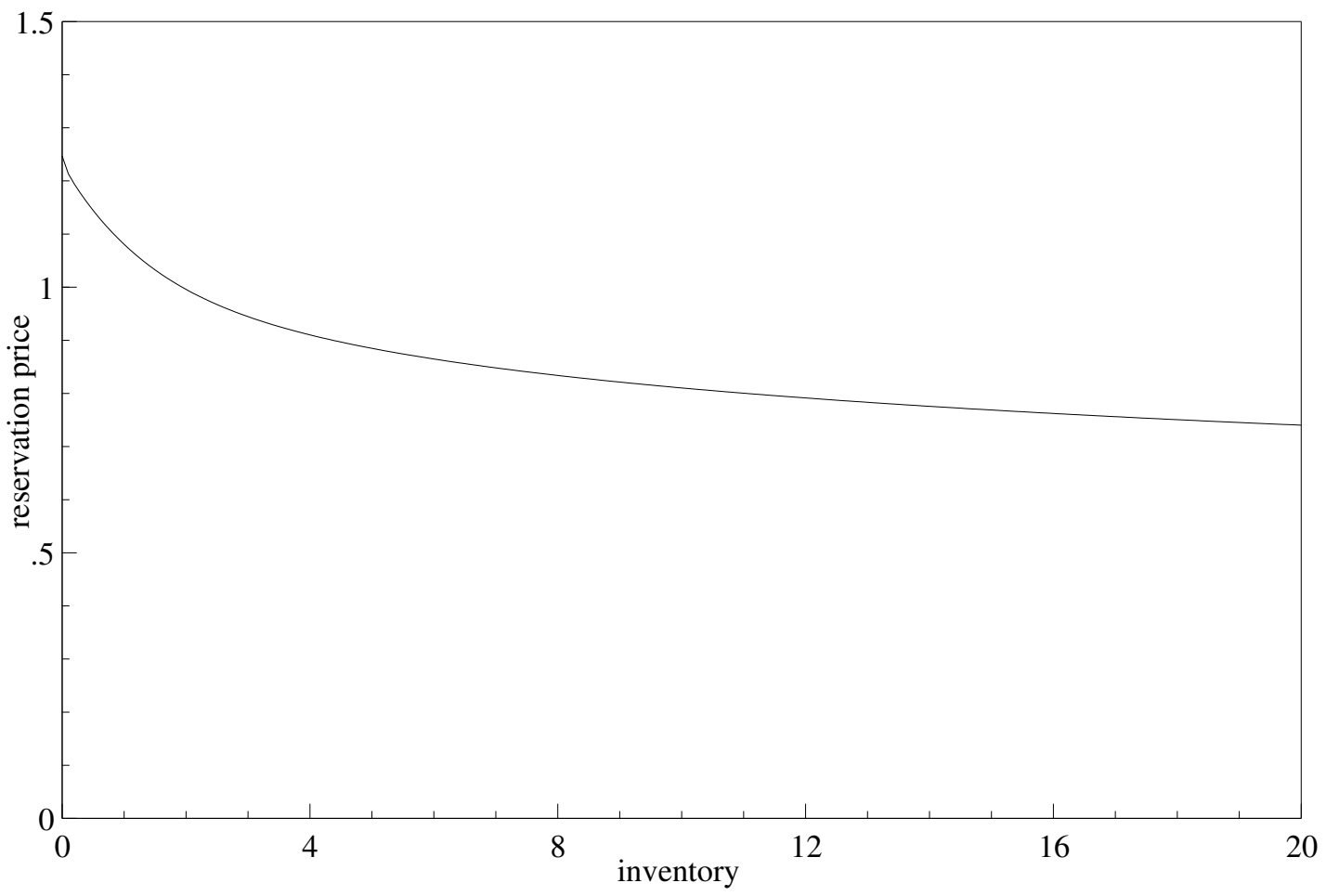

Figure 1: The "reservation price" $V_{i, t}(1)-V_{i, t}(0)$ as a function of the inventory level $S_{i, t}-C_{i, t}$. 